\title{
Effectiveness of Water Infrastructure for River Flood Management: Part 2 - Flood Risk Assessment and Its Changes in Bangladesh
}

\author{
Y. Kwak ${ }^{1}$, M. Gusyev ${ }^{1}$, B. Arifuzzaman ${ }^{2}$, I. Khairul ${ }^{2}$, Y. Iwami ${ }^{1}$, and K. Takeuchi ${ }^{1}$ \\ ${ }^{1}$ International Centre for Water Hazard and Risk Management (ICHARM) under the auspices of UNESCO, \\ Tsukuba, Japan \\ ${ }^{2}$ Bangladesh Water Development Board, Dhaka, Bangladesh \\ Correspondence to: Y. Kwak (kwak55@ @wri.go.jp)
}

Received: 16 March 2015 - Accepted: 16 March 2015 - Published: 11 June 2015

\begin{abstract}
A case study of Bangladesh presents a methodological possibility based on a global approach for assessing river flood risk and its changes considering flood hazard, exposure, basic vulnerability and coping capacity. This study consists of two parts in the issue of flood change: hazard assessment (Part 1) and risk assessment (Part 2). In Part 1, a hazard modeling technology was introduced and applied to the Ganges, Brahmaputra and Meghna (GBM) basin to quantify the change of 50- and 100-year flood hazards in Bangladesh under the present (1979-2003) and future (2075-2099) climates. Part 2 focuses on estimating nationwide flood risk in terms of affected people and rice crop damage due to a 50-year flood hazard identified in Part 1, and quantifying flood risk changes between the presence and absence of existing water infrastructure (i.e., embankments). To assess flood risk in terms of rice crop damage, rice paddy fields were extracted and flood stage-damage curves were created for maximum risk scenarios as a demonstration of risk change in the present and future climates. The preliminary results in Bangladesh show that a tendency of flood risk change strongly depends on the temporal and spatial dynamics of exposure and vulnerability such as distributed population and effectiveness of water infrastructure, which suggests that the proposed methodology is applicable anywhere in the world.
\end{abstract}

\section{Introduction}

Over the last decades, the number of affected people and the scale of economic damage caused by inland flood disasters have considerably increased. Globally, this trend will likely to continue due to the increase in flood magnitude and the lack of preparedness for extreme events (Bates et al., 2008). Especially, Asia is disproportionally influenced by the impacts of flood disasters (WWAP, 2009). For instance, Kwak et al. (2012) demonstrated that the Asian region would be at a higher flood risk throughout the 21st century than ever before, because more extreme rainfall would lead to increase of flood inundation depth in many areas.

Since the early 21 st century, risk reduction of the waterrelated disaster has been globally recognized as a common goal. Starting from the year 2000, eight Millennium Development Goals (MDGs) were declared by 191 nations, and intergovernmental organizations and resolutions were established to address the necessity for practical, policy-neutral risk assessment. Various flood risk assessment methods were proposed, such as the Disaster Risk Index (UNDP, 2004), the National Disaster Hotspot (World Bank, 2005), and the Global Risk Data Platform (Peduzzi et al., 2009). In spite of these great efforts, there is still much room left to improve flood risk assessment as a grand challenge with new technical innovations that can operate effectively even with limited global data. Therefore, many global flood risk assessment methodologies are still lacking a description of actual risk phenomena in developing countries such as Bangladesh, one of the most flood-prone country in the Asian monsoon region. 


\section{Objective}

The ultimate goal of this study was to demonstrate a new approach to develop a global flood risk assessment methodology that takes into account not only flood hazard and exposure but also basic vulnerability and coping capacity. The main objective in this study was to estimate temporal and spatial dynamics of nationwide flood risk changes by 50 -year maximum flood events over Bangladesh in terms of affected people and damaged rice crop. In addition, we also quantified the effectiveness of water infrastructure, i.e., embankments, in flood risk reduction under climate change.

\section{Approach to flood risk assessment}

From the results of flood hazard assessment described in Part 1 of this study, we selected 50-year flood as extreme events based on MRI-AGCM3.2S (SRES A1B scenario) precipitation for the present (1979-2003) and future (2075-2099) climates simulated with a distributed hydrological Block-wise TOP model (BTOP model: Takeuchi et al., 2008) and the GIS-based Flood Inundation Depth (FID) model (Kwak et al., 2012). Then, nationwide flood risk change between the present and future climates was estimated in terms of flood hazard (inundation area, depth and frequency) and exposure (affected people and agricultural damages).

\subsection{Study area}

The study area is the three major rivers, i.e., Ganges, Brahmaputra and Meghna (GBM) in Bangladesh, which is located at the downstream end of the floodplain delta between Latitude $20-27^{\circ} \mathrm{N}$ and Longitude $88-93^{\circ} \mathrm{E}$. The GBM basin area is about $120400 \mathrm{~km}^{2}$, approximately $70 \%$ of the total national land area. Bangladesh faces flood disasters every year due to extreme rainfall and its geographical location. More than 160 million people live in the country, and most of them are directly exposed to floods (BBS, 2011). The agricultural sector accounts for a major share of $30 \%$ to the gross domestic product and employs about $65 \%$ of the nation's workforce. In Bangladesh, rice crop accounts for $94 \%$ of the total crop production and has a paddy area of about $105000 \mathrm{~km}^{2}$ with about $50 \%$ used for Aman rice (BBS, 2011). The Aman rice plant is the most prone to monsoon floods among the three major rice crops in Bangladesh, i.e., Aus, Aman and Boro, because floods occur regularly during Aman's harvesting season (Fig. 1a).

\subsection{Used data}

This study used five primary data for calculating affected people and rice crop damage at each grid pixel (approximately $450 \mathrm{~m}$ ), as listed in Table 1 . First, to simulate inundated areas for hazard assessment, the FID model requires several input data: the maximum daily river discharge from
Part 1, the Gumbel distribution with L-moments from the BTOP model, and topographic data (DEM: digital elevation model) acquired from HydroSHEDS (hydrological data and maps based on the SHuttle Elevation Derivatives at multiple Scale) data (Lehner et al., 2008). Next, flood exposure was calculated in consideration of water infrastructure by combining inundated areas with distributed population data from the LandScan ${ }^{\mathrm{TM}}$ (Budhendra et al., 2007), and paddy field areas extracted from the Global Land Cover dataset by National Mapping Organizations (GLCNMO2008, Tateishi et al., 2014). Finally, flood stage-damage curves of rice crop were developed for flood risk calculation over the GBM basin, which were created by local offices (i.e., districts) and crop calendar (WFP, 2010) based on the 2014 household survey of Bangladesh Water Development Board (BWDB, 2014, Fig. 1b).

\subsection{Estimating flood risk}

\subsubsection{Definition of risk}

It is essential for the definition of risk to comprehend attributes of the physical realm (hazard and exposure) and the meta-physical realm (basic vulnerability and coping capacity). Physical and meta-physical risk components can be separated according to a flood risk definition (Wisner, 1994; UNISDR, 2004). Here, the terms of hazard and exposure come from the physical realm, and thus should be effectively measured by physical methods (hydro-topographic models and demographic distribution data) (Peduzzi et al., 2009; Roberts et al., 2009). Flood risk (FR) was defined as follows:

$\mathrm{FR}=H \times E \times \mathrm{BV} \times \mathrm{CC}$

where $H$ (frequency) is the riverine flood hazard at 50-year return period, $E$ (affected population and agriculture) is the number of people and paddy fields in the flood area, BV (\%) is the basic vulnerability, and $\mathrm{CC}(\mathrm{m})$ is the coping capacity.

This study applied the concept of flood risk (FR) to Bangladesh as a case study. To estimate physical exposure accurately, hazard modeling (Part 1) was reproduced and applied in the GBM basin to quantify the change of 50- and 100-year flood hazard in Bangladesh under the present and future climates. To estimate meta-physical risk components, vulnerability was separated into basic vulnerability and coping capacity. Basic vulnerability conceptually concerns all social factors that increase the risk, but is represented by stage-damage curves in this study (Fig. 1b). Coping capacity refers to factors of governments' efforts for disaster risk reduction. In order to reduce conceptual ambiguity, water infrastructure (i.e., embankment) is selected as coping capacity in this study.

\subsubsection{Flood exposure and risk assessment}

Large flood events cause damage risk to human fatality and damage loss, i.e., agricultural damage. Hazard and exposure 

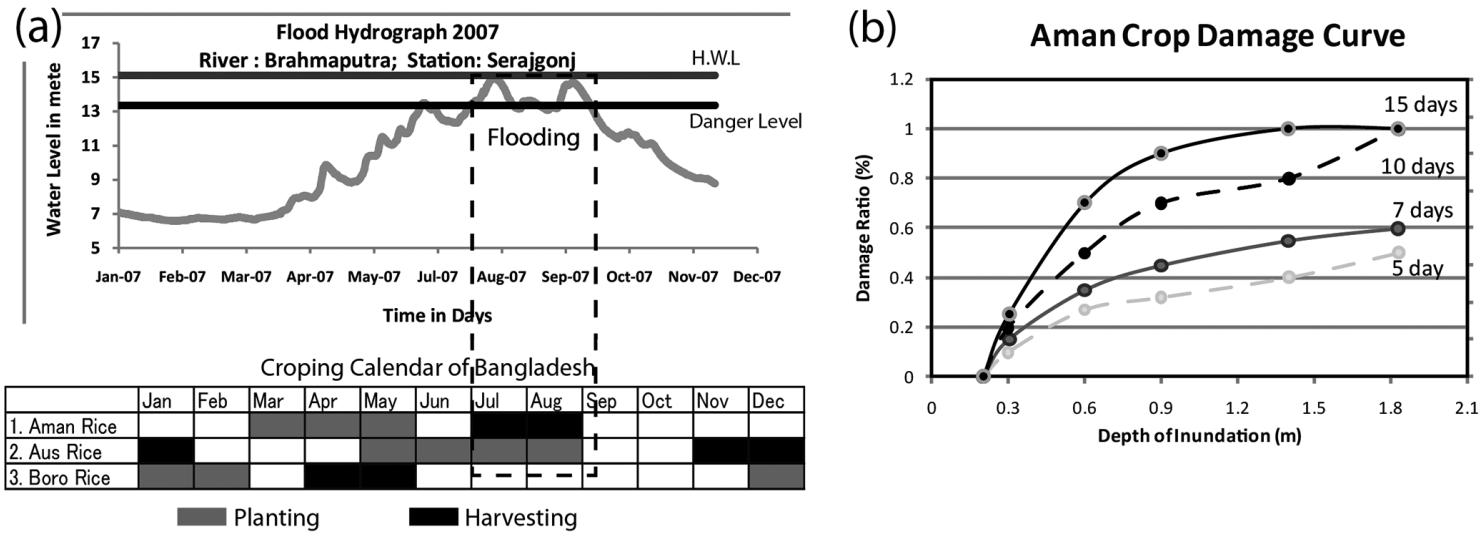

Figure 1. The relationship of flood characteristics between the hydrograph and crop calendar due to Monsoon flooding from July to September (WFP, 2010) (a), and flood stage-damage curves of Aman rice crop (b).

Table 1. The characteristics of spatial distribution data.

\begin{tabular}{lll}
\hline Used data & Raster resolution & Source \\
\hline River discharge & $20 \mathrm{~km}(10 \mathrm{~min})$ & BTOP model (2014) \\
Topographic data & $90 \mathrm{~m}$ to $0.45 \mathrm{~km}(15 \mathrm{arcsec})$ & HydroSHEDS (2008) \\
Land cover & $0.45 \mathrm{~km}(15 \mathrm{arcsec})$ & GLCNMO (2008) \\
Population data & $1 \mathrm{~km}(30 \mathrm{arcsec})$ & LandScan $(2009)$ \\
Water level \& Stage-damage curves & 84 gauge stations & BWDB (2014) \\
\hline
\end{tabular}

from the physical realm can be integrated into physical exposure (population and paddy fields in this study area affected by a hazard).

1. Exposure assessment: Exposure was calculated by combining a flood area with a digital distributed population map from the LandScan ${ }^{\mathrm{TM}} 2009$ data with the focus on estimating changes in affected people considering water infrastructure (i.e., embankment) and natural conditions. Future affected population was estimated based on the present affected population by using Eq. (2) as follows:

Pop $_{\text {future }}=(1+r)$ Pop $_{\text {present }}$

where Pop is the affected population at present and in the future in case of an extreme flood of 50-year return period, and $r$ is the population growth ratio (CIESIN, 2013).

2. Flood risk assessment: Flood stage-damage curves of the Aman rice crop were derived from local data collected from farmers in several flood prone regions that suffered from damage in the 2012, 2013 and 2014 floods in the Brahmaputra River basin. The Aman rice crop is transplanted and grows during the June-August period. Its production is greatly affected by monsoon floods, which is a regular event in Bangladesh according to the rice crop calendar (Fig. 1a). An extreme monsoon flood causes the Aman rice crop significant damage at the transplanting and pre-growing stages. To estimate damage to the Aman rice crop, the paddy field areas were extracted from GLCNMO2008, and maximum damage curve of 15-day was applied based on flood exposure identified in this study.

\section{Results}

Preliminary results show that a propensity of extreme flood risk changes strongly depends on the temporal and spatial dynamics of exposure and vulnerability such as distributed population and effectiveness of water infrastructure. Results of the flood exposure and risk assessment are summarized in the following sections.

\subsection{Physical exposure assessment}

(1) Physical exposure assessment: Table 2 shows the changes in potential 50-year flood inundation area and affected people in the GBM basin of Bangladesh between the present and future climates in consideration of water infrastructure effectiveness. Figure 2a shows the difference of FID results in 50-year flood inundation area during the present climate with and without water infrastructure. Collectively, they suggest that water infrastructure should be effective, reducing affected people by $35 \%$ from 64 million without embankments to 42.7 million with embankments. By counting the 


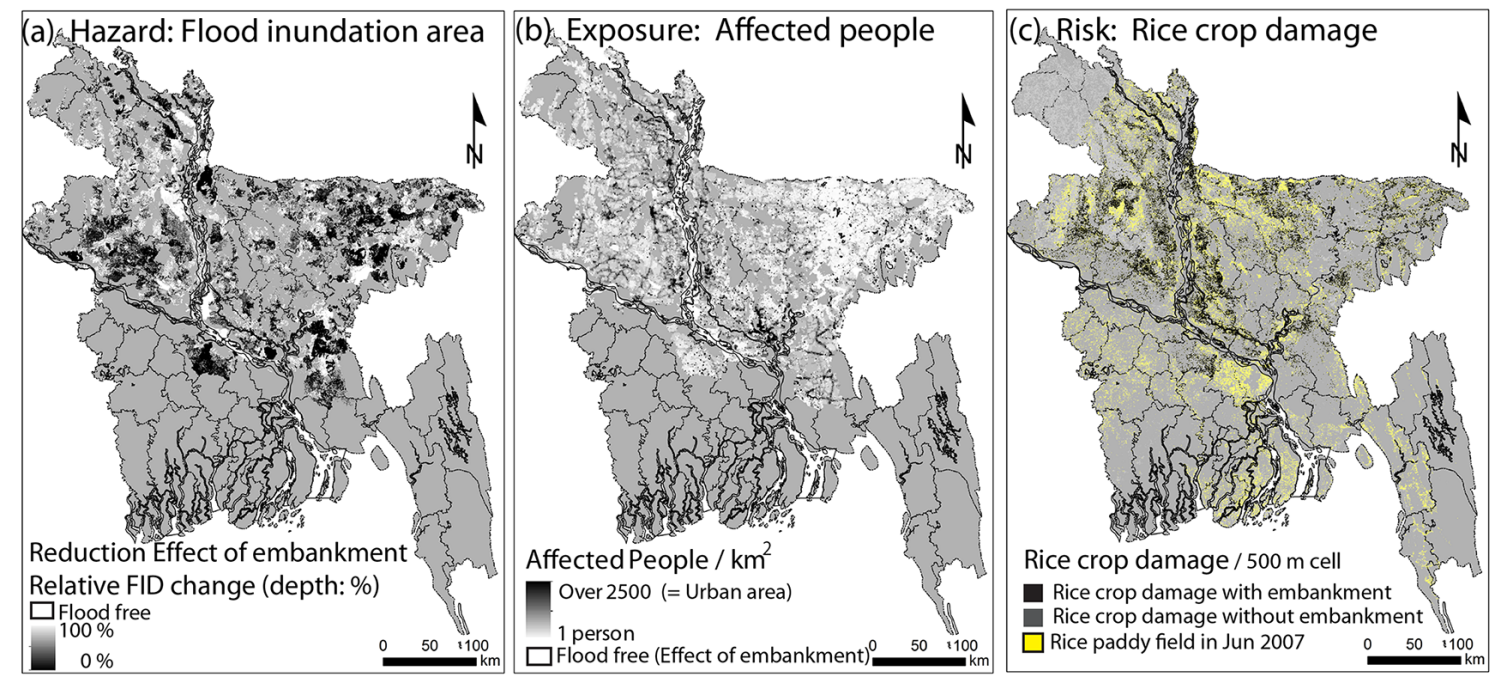

Figure 2. The impact of the physical flood hazard according to water infrastructure effectiveness (a), potential exposure (b), and potential risk of rice crop damage (c), in case of 50-year flood during the present climate over the GBM basin in Bangladesh.

Table 2. The changes in potential 50-year flood inundation area and affected people by water infrastructure effectiveness in the GBM basin of Bangladesh between the present and future climates.

\begin{tabular}{lrrrr}
\hline Time-slice climate experiments & \multicolumn{2}{c}{ The present (1979-2003) } & \multicolumn{2}{c}{ The future (2075-2099) } \\
\hline Infrastructure & Embankment & Without embankment & Embankment & Without embankment \\
Inundation area $\left(\mathrm{km}^{2}\right)$ & 47600 & 73790 & 50240 & 76860 \\
Affected people (Mil.) & 42.7 & 64.0 & 54.2 & 67.5 \\
Relative change (\%): & - & - & $+25 \%$ & $+6 \%$ \\
(Present-Future)/Present & \multicolumn{2}{c}{$35 \%$ reduction } & $34 \%$ reduction \\
Infrastructure effect (\%) & \multicolumn{2}{c}{} & & \\
\hline
\end{tabular}

population in the inundation area with embankments, Table 2 also reveals that the number of affected people may increase from 42.7 million in the present climate to 54.2 million in the future climate, without further improvement of water infrastructure. In Fig. 2b, the black cells show a high-level risk (over 2500 person per $\mathrm{km}^{2}$ of urban area), and the white cells show a low-level risk or flood free of physical exposure (one person or more affected by flooding) corresponding to the potential flood hazard areas (over $0.1 \mathrm{~m}$ of FID) which are protected by embankments.

\subsection{Physical risk damage calculation}

Physical flood damage was calculated and showed the possibility to produce a large-scale map for the estimation of rice crop damage from potential FID and flood stage-damage curves. The output map is presented in Fig. $2 \mathrm{c}$ with two different levels of rice crop damage in the 50-year flood during the present climate with and without water infrastructure. By counting the damaged area according to water embankment effectiveness, the area of rice crop damage was estimated to reduce by about $3.4 \%$ in the present climate while it may in- crease by about $4.6 \%$ in the future climate. In particular, 6 districts, located near the Buramputra River, were predicted to be exposed to more high-risk areas in the future climate than in the present climate.

\section{Conclusions}

Although the development of our approach is at the preliminary stage, particularly for flood risk assessment, it has been demonstrated to be promising as a reasonable method for long-term prediction of flood risk changes of the maximum potential flood events. Flood risk assessment was tested for part of the GBM basin in Bangladesh by using FID and depended on simulated flood hazard and exposure modeling. The preliminary results of the physical flood hazard modeling were validated with field survey, observed satellite images and historical data to represent nationwide flood exposure and risk. According to the maximum flood risk scenario, the meta-physical risk changes in terms of potentially affected people and possible damage loss showed a clear relation between water infrastructure effectiveness and climate change impacts over Bangladesh in the present and future 
climates even model uncertainties. This study also provides a basis for appropriate policy and management decisions by governments and international organizations on the reduction of disaster impacts. The proposed approach shows a methodological possibility for global flood risk assessment. Further research should be carried out on more detailed and evidence-based databases (e.g., sub-basin scale) to identify patterns of various flood disasters.

Acknowledgements. This research is supported by the Japan Society for the Promotion of Science (JSPS) KAKENHI Grant-inAid for Young Scientists (B: 24710211). We would like to thank Mr. Masahiko Okubo at ICHARM for his editorial support in finalizing this manuscript.

\section{References}

BBS (Bangladesh Bureau of Statistics), Agriculture Wing, Annual Report, 2011.

BWDB (Bangladesh Water Development Board): Observed river data and reports of 1988, 1998, and 2004 floods, available at: http://www.bwdb.gov.bd, 2014.

Bates, B. C., Kundzewicz, Z. W., Wu, S., and Palutikof, J. P.: Climate Change and Water. Technical. Paper of the Intergovernmental Panel on Climate Change, IPCC Secretariat, Geneva, 210, 2008.

Budhendra, B., Bright, E., Coleman, P., and Urban, M.: the LandScan $^{\mathrm{TM}}$ USA: a high-resolution geospatial and temporal modeling approach for population distribution and dynamics, GeoJournal, 69, 103-117, doi:10.1007/s10708-007-9105-9, 2007.

CIESIN (Center for International Earth Science Information Network) Columbia University: Low Elevation Coastal Zone (LECZ) Urban-Rural Population and Land Area Estimates, Version 2. Palisades, NY: NASA Socioeconomic Data and Applications Center (SEDAC), 2013.

Kwak, Y., Takeuchi, K., Fukami, J., and Magome, J.: A new approach to flood risk assessment in Asia-Pacific region based on MRI-AGCM outputs, Hydrol. Res. Lett., 6, 55-60, doi:10.3178/hrl.6.70, 2012.
Lehner, B., Verdin, K., and Jarvis, A.: New global hydrography derived from spaceborne elevation data, EOS Trans., AGU, 89, 93 94, doi:10.1029/2008EO100001, 2008.

Peduzzi, P., Dao, H., Herold, C., and Mouton, F.: Assessing global exposure and vulnerability towards natural hazards: the Disaster Risk Index, Nat. Hazards Earth Syst. Sci., 9, 1149-1159, doi:10.5194/nhess-9-1149-2009, 2009.

Roberts, N. J., Nadim, F., and Kalsners, B.: Quantification of vulnerability to natural hazards, Georisk, 3, 164-173, doi:10.1080/17499510902788850, 2009.

Takeuchi, K., Hapuarachchi, P., Zhou, M., Ishidaira, H., and Magome, J.: A BTOP model to extend TOPMODEL for distributed hydrological simulation of large basins, Hydrol. Process., 22, 3236-3251, doi:10.1002/hyp.6910, 2008.

Tateishi, N., Hoan, N., Kobayashi, T., Alsaaideh, B., Tana, G., and Phong, D.: Production of Global Land Cover Data - GLCNMO2008, J. Geogr. Geol., 6, 99-122, doi:10.5539/jgg.v6n3p99, 2014.

UNDP (Development Programme) : Reducing disaster risk: a challenge for development, a global report, Bureau for Crisis and Recovery, John S. Swift, 1-117, 2004.

UNISDR (United Nations Inter-Agency Secretariat of the International Strategy for Disaster Reduction): Living with risk: a global review of disaster reduction, Volume II Annexes, 2004.

Wisner, Benjamin: At Risk: Natural Hazards, Peoples Vulnerability and Disasters, London: Routledge, Taylor \& Francis books, 1994.

World Bank: Natural Disaster Hotspots: Case Studies, Disaster Risk Management Series, 1-184, 2005.

WFP (World Food Program): Bangladesh Food Security Monitoring Bulletin Issue No. 2, August-October 2010.

WWAP (World Water Assessment Programme) The United Nations World Water Development Report 3: Water in a Changing World. Paris: UNESCO Publishing and London: Earth scan, 2-24, available at: http://www.unesco.org/water/wwap/wwdr/wwdr3/, 2009. 